\title{
THE INFLUENCE OF ROCKMASS PROPERTIES AT THE PLASTIC ZONE AROUND A CIRCULAR TUNNEL
}

\author{
Antoniou A. ${ }^{1}$ and Spyropoulos $\mathbf{I}^{2}$ \\ ${ }^{1}$ National Technical University of Athens, School of Civil Engineering, Department of \\ Geotechnics, andreasan19@yahoo.com, \\ ${ }^{2}$ DOMI S.A., 14 Korgialeniou St.r., 115 21, Athens
}

\begin{abstract}
Tunneling in weak rock has to be carefully designed since the overestimation of weak rock mass properties or the underestimated design and behaviour of the support system can lead to increased cost or even to failure. Based on the generalized HoekBrown failure criterion this paper presents relation between geometrical parameters (tunnel's radius, depth, etc) and rock's mass parameters (GSI, mi, etc) with the extension of plastic zone around a circular tunnel, as well as the wall displacement of an unsupported circular tunnel. All the analyses were executed considering hydrostatic stress field and isotropic behaviour of the surrounding rock mass.

Key words: weak rock, unsupported tunnel, shallow tunnel.
\end{abstract}

\section{Пєрí $\eta \psi \eta$}

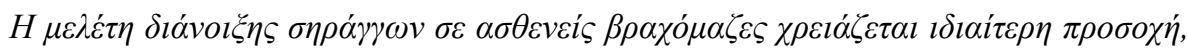

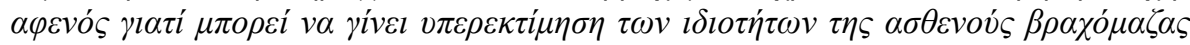

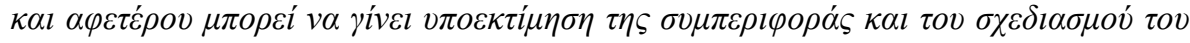

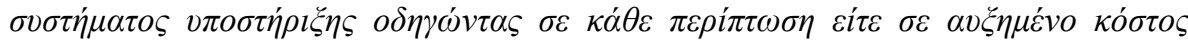

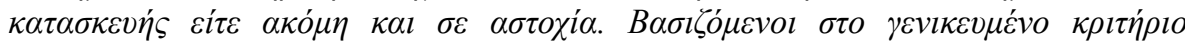

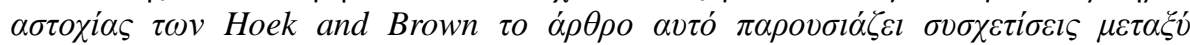

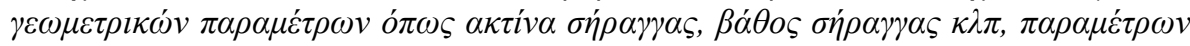

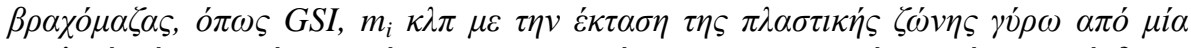

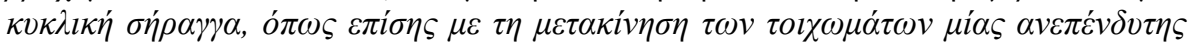

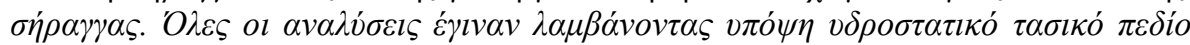

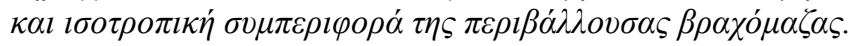

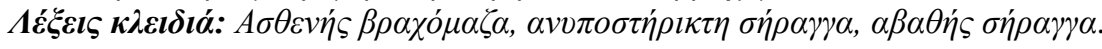

\section{Introduction}

Understanding the failure mechanism of a rock mass surrounding an underground opening is necessary for the design of support systems for the openings. In any case this mechanism depends on the in situ stress level and the characteristics of the rock mass. Usually at shallow depths, where rock mass strength is controlled from weathering processes and is presented jointed the stability problems are related with wedge free falls or slides from the roof or side walls of the opening. As the depth below ground surface is increased, the in situ stresses increased and may reach a level at 
which the failure of the rock mass is induced. In that case the failure can include spalling, slabing and rock burst.

An ideal condition could be excavation of an underground opening in unweathered massive rock mass paired together with low in situ stress, where the deformation is relatively low and the necessity of support is limited. Unfortunately this condition is not very common, especially in Greece due to the complexity of the geological environment, leading to a complex in situ stress field. On the other hand many tunnels have been constructed successfully in Greece the last two decades and their design for the temporary lining was based to finite element analysis.

Due to the size of tunnel openings in most infrastructures, the rock around the tunnel behaves more like a discontinuum. Behavior of a tunnel in a continuous material depends on the intrinsic strength and deformation properties of that material, leading to analytical modeling whereas behavior of a tunnel in a discontinuous material depends on the character and spacing of the discontinuities, leading to consider possible wedge movement or failure. Thus the behavior of the tunnel is a combination of a blocky medium and a continuum and only to soft rock or to a small tunnel in a massive rock, where the distance between joints is greater than tunnel's diameter the assumption of a continuous material can be used.

As the depth of a tunnel becomes greater or the ground conditions become unfavorable, the stress within the surrounding mass increases and failure occurs when the stress exceeds the strength of the rock mass. The failure type can be spalling, or slabbing or even a rock burst leading to significant rock volume's failure.

The analyses present herein through RocSupport computer program of RocScience, assume that the rock mass exhibits elastic-perfectly plastic failure, presents isotropic behavior and the in situ stress field constitutes from equal principle stresses. In case of non hydrostatic stress field, more complex rock masses, or other than circular tunnel, RocSupport can not predict the convergence and more sophisticated computer programs should be used, for example finite element analysis, since these simplifying assumptions mean that important bending moments and shear forces can be induced in the lining and these may result in premature failure of the support systems (Hoek, 2012).

\section{Deformation Around an Advancing Tunnel, Definition of Failure Criterion and Tunnel Behaviour}

The state of stress due to tunnel excavation can be calculated from analytical elastic closed form solutions. Kirsch's elastic closed form solution is one of the most commonly used analytical solutions, but can be applied to simple geometry tunnel and to limited stress field; thus its practical use is limited. However it is considered as a very practical tool to check results from numerical analysis. Figure 1 presents deformations ahead, on and behind tunnel face (Hoek, 1998a). Elastic deformation of the rock mass starts about two tunnel diameters ahead of the advancing face and reaches its maximum value at about two diameters behind the face, while at the tunnel's face position about one third of the total radial inward deformation of the tunnel has already occurred. The assumption that these deformations affect the stability of the tunnel depends on the ratio between the rock mass strength and the in situ applied stress.

Hoek (1998b) presented a very simple analytical model based on Mohr-Coulomb failure criterion, where a circular tunnel is subjected to a hydrostatic stress filed and is driven in a homogeneous rock mass which behaves as an elastic - perfectly plastic material, in which failure involving slip along intersecting discontinuities is assumed to occur with zero plastic volume change (DancanFama, 1993).

According to this the plastic failure is defined by Mohr-Coulomb criterion and is expressed as: 


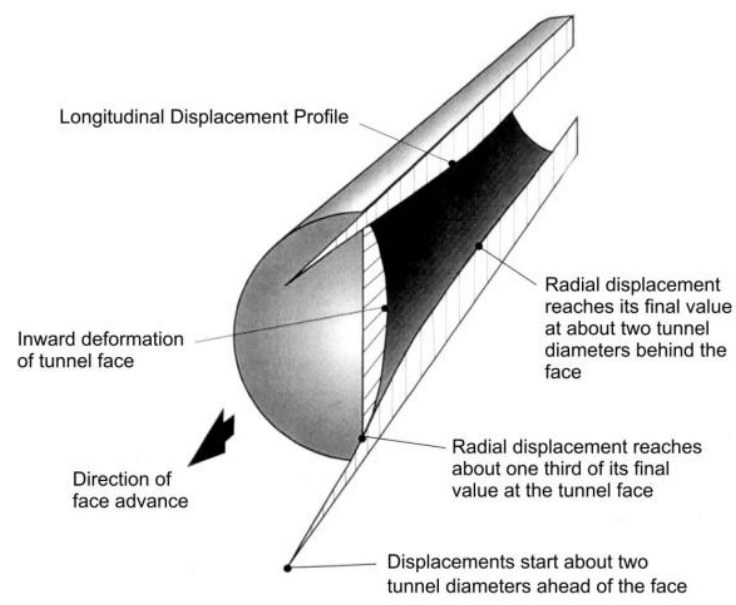

Figure 1 - Radial and longitudinal deformations ahead, on and behind tunnel's face (after Hoek, 1998a).

\section{Equation 1 - Plastic failure defined by Mohr-Coulomb criterion}

$$
\sigma_{1}^{\prime}=\sigma_{c m}+k \sigma_{3}^{\prime}
$$

where the uniaxial compressive strength of the rock mass $\sigma_{\mathrm{cm}}$ is calculated as:

\section{Equation 2 - Uniaxial compressive strength of the rock mass}

$$
\sigma_{c m}=\frac{2 c^{\prime} * \cos \phi}{1-\sin \phi}
$$

and $\mathrm{k}$ is expressed as

\section{Equation 3 - Calculation formulae of parameter $k$}

$$
k=\frac{1+\sin \phi}{1-\sin \phi}
$$

where $\sigma_{1}{ }^{\prime}$ is the axial stress where failure occurs

$\sigma_{3}{ }^{\prime}$ is the confining stress

$c^{\prime}$ is the cohesion

$\varphi^{\prime}$ is the friction angle of rock mass

According to Hoek (1998b) the surrounding rock mass of a circular tunnel of radius $r_{0}$ which is subjected to hydrostatic pressure $\mathrm{p}_{0}$ and to uniform support pressure $p_{i}$ will fail when the internal pressure $p_{i}$ is less than the critical support $p_{c r}$ defined by:

\section{Equation 4 - Calculation of the critical support $p_{\text {cr }}$}

$$
p_{c r}=\frac{2 * p_{0}-\sigma_{c m}}{1+k}
$$

If the internal support pressure $p_{i}$ is greater than the critical support pressure $p_{c r}$, no failure occurs, the behavior of the rock mass surrounding the tunnel is elastic and the inward radial elastic 
displacement $u_{i}$ of the tunnel wall is given by:

Equation 5 - Calculation of the inward radial elastic displacement $u_{i}$ of the tunnel wall

$u_{i}=\frac{r_{0} *(1+v) *\left(p_{0}-p_{i}\right)}{E_{m}}$

where $E m$ is the deformation modulus and

$v$ is the Poisson's ratio.

In case where the internal support pressure $p_{i}$ is less than the critical support pressure $p_{c r}$, then failure occurs and the radius $r_{\mathrm{p}}$ of the plastic zone around the tunnel is given by:

Equation 6 - Calculation of the radius $r_{p}$ of the plastic zone around the tunnel

$r_{p}=r_{0}\left[\frac{2 *\left(p_{0} *(k-1)+\sigma_{c m}\right)}{(1+k) *(k-1) * p_{i}+\sigma_{c m}}\right]^{\frac{1}{k-1}}$

and the inward radial plastic displacement $u_{i}$ of the tunnel wall is given by:

Equation 7 - Calculation of the inward radial plastic displacement ui of the tunnel wall

$u_{i}=\frac{r_{0} *(1+v)}{E}\left[2 *(1-v) *\left(p_{0}-p_{c r}\right) *\left(\frac{r_{p}}{r_{0}}\right)^{2}-(1-2 v) *\left(p_{0}-p_{i}\right)\right]$

\section{Tunnel Deformation Analysis}

\subsection{Introduction}

One of the major problems in rock is that of estimating the strength of the rock mass which usually comprises of an interlocking matrix of discrete but uneven blocks with various degrees of weathering, while the contact surfaces between the blocks may vary from clean and fresh to clay covered and slickensided. Determination of the strength of an in situ rock mass by laboratory testing is generally not practical; therefore this strength must be estimated from geological observations and from test results on individual rock pieces or rock surfaces which have been removed from the rock mass. The answer to this problem was given through the empirical failure criterion of Hoek and Brown (1980).

The most important component of the Hoek- Brown criterion is the process of reducing the material constants $\sigma_{\mathrm{ci}}, \mathrm{m}_{\mathrm{i}}$ and modulus of elasticity $\mathrm{E}$, determined as "laboratory" values to appropriate in situ values. This is accomplished through the Geological Strength Index (GSI), which is a chart combined structural and surface conditions in order to detail the geological conditions existing in nature. Note that although Hoek and Brown criterion assume that the rock mass behaves isotropically, the behavior of the rock mass is usually controlled by movement and rotation of rock blocks separated by intersecting structural features such as discontinuities and joints. Hoek (1998a) used the - presented in the previous paragraph analytical model where a circular tunnel is subjected to a hydrostatic stress filed and is driven in a homogeneous rock mass which behaves as an elastic and perfectly plastic material - criterion and examined through a Monte Carlo analysis 2000 iterations for uniform distributions of a rock mass properties, tunnel 
radius and in situ stress level in order to explore the concepts of rock support interaction. In his analyses the rock mass properties were varied from fair $(G S I=35)$ to extremely poor $(G S I=5)$, corresponding to the properties of weak sandstones and mudstones down to material that can almost be classified as soil, while Hoek and Kazurlovic (2000) in their analyses denote that the value of GSI equal to 25 refers to rock masses of good to reasonable quality. The in situ stresses $\left(p_{0)}\right.$ were varied from 2 to $20 \mathrm{MPa}$, corresponding to depths below surface from 75 to $750 \mathrm{~m}$, and the tunnel diameters were varied from 4 to 16 meters. The results of this analysis are presented through equations 8 and 9 which estimate the diameter of the zone of plastic failure $\left(d_{p}\right)$ and the closure of the tunnel $\left(\delta_{i}\right)$ as ratios of in situ uniaxial rock mass strength to in situ stress and support pressures. Note that in these equations the in situ uniaxial rock mass strength is calculated by using equation 10.

Equation 8 - Tunnel deformation versus support pressure

$$
\frac{\delta_{i}}{d_{0}}=\left(0.002-0.0025 \frac{p_{i}}{p_{0}}\right){\frac{\sigma_{c m}}{p_{0}}}^{\left(2.4 \frac{p_{i}}{p_{0}}-2\right)}
$$

Equation 9 - Size of plastic zone versus support pressure

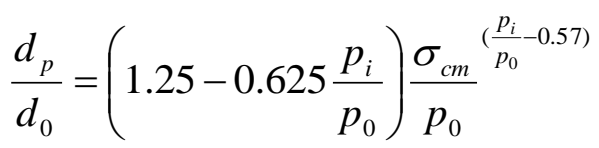

$\delta i=$ Tunnel sidewall deformation

$d o=$ Original tunnel radius in meters

$p i=$ Internal support pressure

$p o=$ In situ stress $=$ depth $\cdot$ unit weight of rock mass

$\sigma c m=$ Rock mass strength $=2 c \cos \phi /(1-\sin \phi)$

$d p=$ Plastic zone radius

Equation 10 - Calculation of the insitu uniaxial rock mass strength

$\sigma_{c m}=\sigma_{c i} * 0.019 * e^{\left(0,05^{*} G S I\right)}$

In a later version of Hoek Brown failure criterion (Hoek et al, 2002) the in situ uniaxial rock mass strength is calculated by the following equation:

\section{Equation 11 - Calculation of the in situ uniaxial rock mass strength}

$\sigma_{c}=\sigma_{c i} * s^{\alpha}$

where:

\section{Equation 12 - Calculation of the parameter $s$}

$$
S=e^{\left(\frac{G S I-100}{9-3 D}\right)}
$$

Equation 13 - Calculation of the parameter $\alpha$

$$
\alpha=\frac{1}{2}+\frac{1}{6}\left(e^{-\frac{G S I}{15}}-e^{\frac{-20}{3}}\right)
$$


while $\mathrm{D}$ is a factor which depends upon the degree of disturbance to which the rock mass has been subjected by blast damage and stress relaxation.

\subsection{Evaluation of the Parameters Used in the Analyses}

Table 1 presents the values of parameters that were used in the presented hereinafter analyses. Wherever necessary the later version of Hoek Brown failure criterion was applied.

Table 1 - Parameters and their values that have been used in the analyses.

\begin{tabular}{|c|c|c|}
\hline Parameter & \multicolumn{2}{|c|}{ Value } \\
\hline Geological Strength Index (GSI) & \multicolumn{2}{|c|}{$5-45$} \\
\hline Strength of intact rock $\sigma_{\mathrm{ci}}(\mathrm{MPa})$ & \multicolumn{2}{|c|}{$5-20$} \\
\hline Material constant $\mathrm{m}_{\mathrm{i}}$ & \multicolumn{2}{|c|}{$9-25$} \\
\hline Thickness of overburden (m) - In situ stress (MPa) & $15-135$ & $0.405-3.605$ \\
\hline Tunnel radius & \multicolumn{2}{|c|}{$3-10$} \\
\hline
\end{tabular}

\subsubsection{GSI}

Marinos and Hoek (2000) denote that the petrographic characteristics of each rock do not allow all the possible combinations derived from the following chart to exist in a geological environment. For instance a limestone mass can not present less than "fair" conditions in its discontinuities and the same time a thin bedded rock can not present better structural conditions than "seamy". Having this remark in mind, Figure 2 presents the variation of GSI values used in our analyses (hatched area).

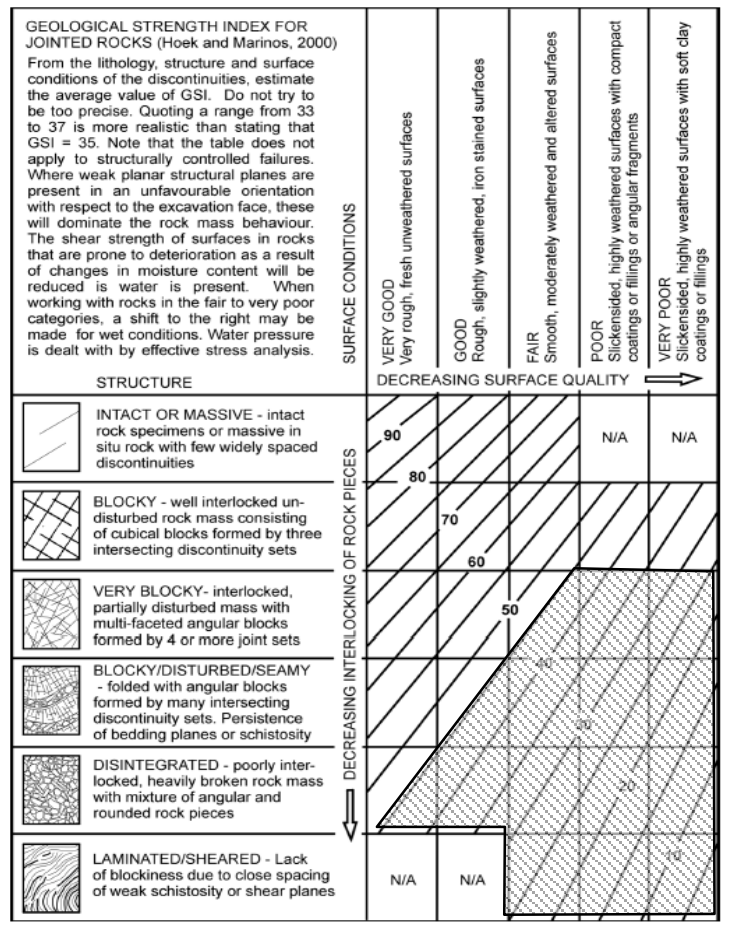

Figure 2 - Variation of GSI values' according to rock mass structure's and surface conditions of joints.

$\underline{\text { XLVII, No } 3-1679}$ 


\subsubsection{Strength of Intact Rock}

Brown (1981) titled "very weak" and "weak" rock masses where their uniaxial compression strength varied from 5 to $25 \mathrm{MPa}$, while Hoek (2002) denoted that a rock mass is considered to be weak when its in situ uniaxial compressive strength is less than about one third of the in situ stress acting upon the rock mass through which the tunnel is being excavated. In the analyses presented hereinafter values between 5 and $20 \mathrm{MPa}$ were used for the uniaxial compressive strength.

\subsubsection{Strength of Intact Rock}

Rocks such as shales, mudstones, siltstones, phyllites and tuffs are typical weak rocks in which even moderate in situ stresses are likely to induce failure in the rock surrounding underground excavations. Usually the uniaxial compressive strength and the material constant $\mathrm{m}_{\mathrm{i}}$ are determined by laboratory testing or are estimated from published tables; the extraction of their values by statistical analysis of the results of a set of triaxial tests on carefully prepared core samples is highly preferred. Additionally, the $\mathrm{m}_{\mathrm{i}}$ parameter depends upon the frictional characteristics of the component minerals in the intact rock sample and it has a significant influence on the strength characteristics of rock. The values for mi parameter were varied from 9 to 25 , trying to refer to as many rock materials as possible.

\subsection{Results - Conclusions}

Taking into account the abovementioned remarks, the following figures present the results of the analyses. Table 2 present the calculated equation for convergence of an unsupported tunnel and radius of plastic zone for specific values of $\mathrm{m}_{\mathrm{i}}$, while Figures 3 and 4 show a remarkable change in the radius of the plastic zone and the closure of the tunnel when the ratio of in situ uniaxial rock mass strength to in situ stress falls below a critical level, while. As it can be seen from the diagrams for tunnels at great depths, the displacements and the plastic zone are significantly large. The demands on the support system may be such that it may be very difficult to support a large tunnel in poor ground at considerable depth below surface (Hoek, 1998a).

Table 2 - Convergence of an unsupported tunnel and radius of plastic zone for specific values of $\mathbf{m}_{\mathbf{i}}$.

\begin{tabular}{|c|c|c|c|c|}
\hline $\mathbf{m}_{\mathbf{i}}$ & Equation & $\mathbf{R}^{2}$ & Equation & $\mathbf{R}^{2}$ \\
\hline $9-25$ & $\frac{\delta_{l}}{D}=0.007 *{\frac{\sigma_{c m}}{p_{0}}}^{-1.329}$ & 0.94 & $\frac{r_{p}}{D}=0.76 *{\frac{\sigma_{c m}}{p_{0}}}^{-0.38}$ & 0.75 \\
\hline 9 & $\frac{\delta_{t}}{D}=0.007 *{\frac{\sigma_{c m}}{p_{0}}}^{-1.474}$ & 0.95 & $\frac{r_{p}}{D}=0.70 *{\frac{\sigma_{c m}}{p_{0}}}^{-0.53}$ & 0.86 \\
\hline 13 & $\frac{\delta_{t}}{D}=0.007 *{\frac{\sigma_{c m}}{p_{0}}}^{-1.369}$ & 0.96 & $\frac{r_{p}}{D}=0.75 *{\frac{\sigma_{c m}}{p_{0}}}^{-0.41}$ & 0.86 \\
\hline 17 & $\frac{\delta_{t}}{D}=0.007 *{\frac{\sigma_{c m}}{p_{0}}}^{-1.288}$ & 0.96 & $\frac{r_{p}}{D}=0.78 *{\frac{\sigma_{c m}}{p_{0}}}^{-0.34}$ & 0.85 \\
\hline 25 & $\frac{\delta_{l}}{D}=0.007 *{\frac{\sigma_{c m}}{p_{0}}}^{-1.184}$ & 0.95 & $\frac{r_{p}}{D}=0.82 *{\frac{\sigma_{c m}}{p_{0}}}^{-0.26}$ & 0.85 \\
\hline
\end{tabular}

Figures 5 to 7 present the closure of an unsupported tunnel related to uniaxial compressive strength $\sigma_{\mathrm{ci}}$, tunnel's depth, GSI and $\mathrm{m}_{\mathrm{i}}$ of the surrounded rock mass. The diagrams clearly depict that for tunnel's depth greater than 40m, GSI values less than 30 and low value of uniaxial compressive strength $(\sigma \mathrm{ci}=5 \mathrm{MPa})$, the convergence of the tunnel is significantly large, while the deformations present low values for all examined depths and especially for GSI values greater than

$\underline{\text { XLVII, No } 3 \text { - } 1680}$ 
15 and values of uniaxial compressive strength greater than 10MPa.

Finally Figure 8 presents the radius of plastic zone of an unsupported tunnel related to tunnel's depth, GSI and $\mathrm{m}_{\mathrm{i}}$ of the surrounded rock mass while uniaxial compressive strength $\sigma_{\mathrm{ci}}$, is equal to $5 \mathrm{MPa}$. From the diagram is clearly depicted that for GSI values less than 15 and depths greater than $40 \mathrm{~m}$ the radius of plastic zone is more than ten times tunnel's radius.

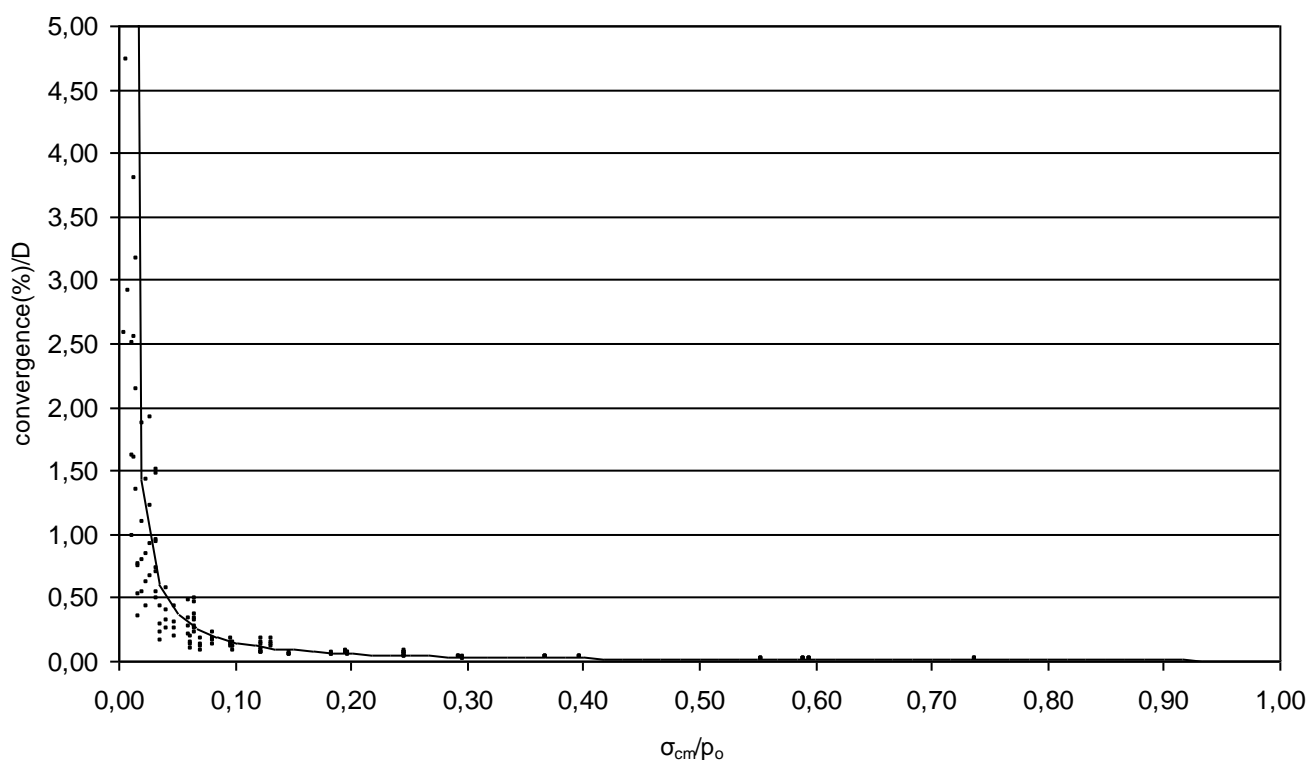

Figure 3 - Convergence of a tunnel versus ratio of in situ uniaxial rock mass strength to in situ stress.

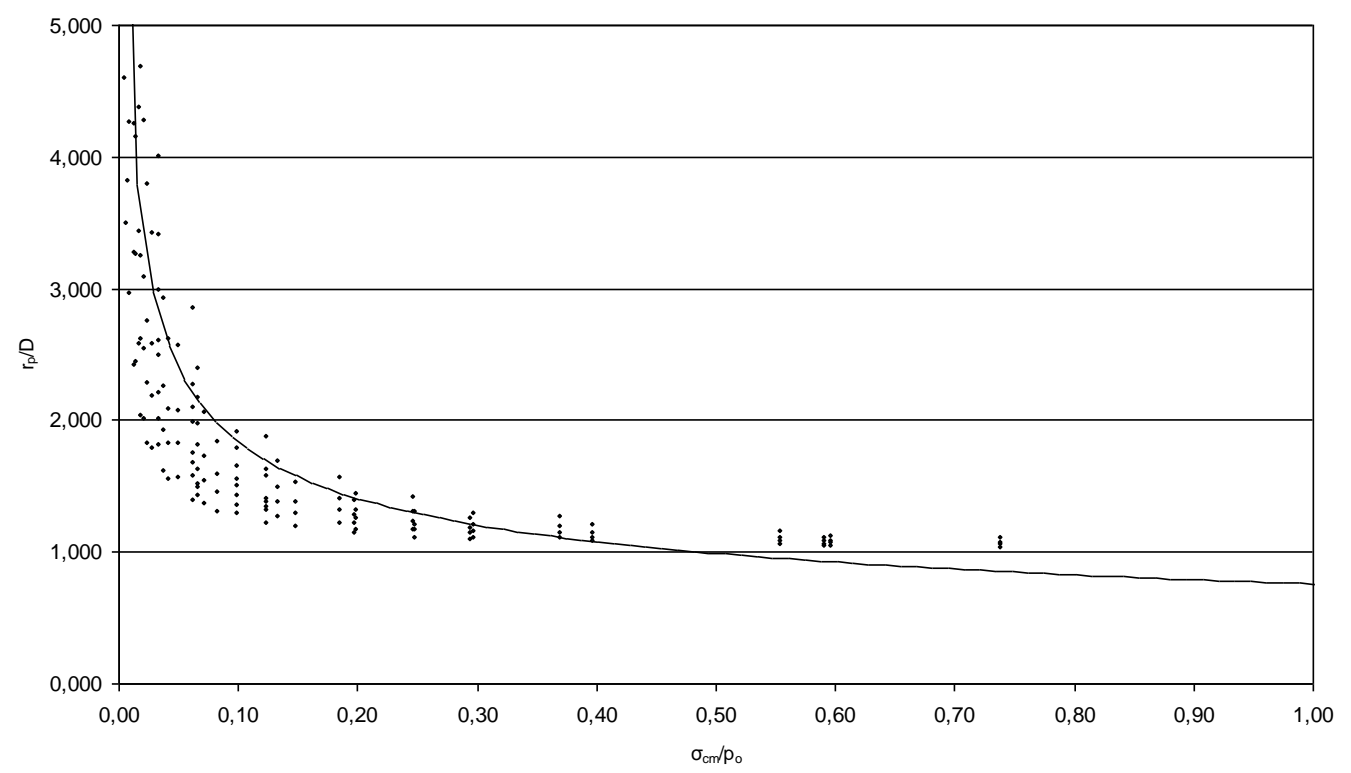

Figure 4 - Tunnel's radius versus ratio of in situ uniaxial rock mass strength to in situ stress.

$\underline{\text { XLVII, No } 3-1681}$ 


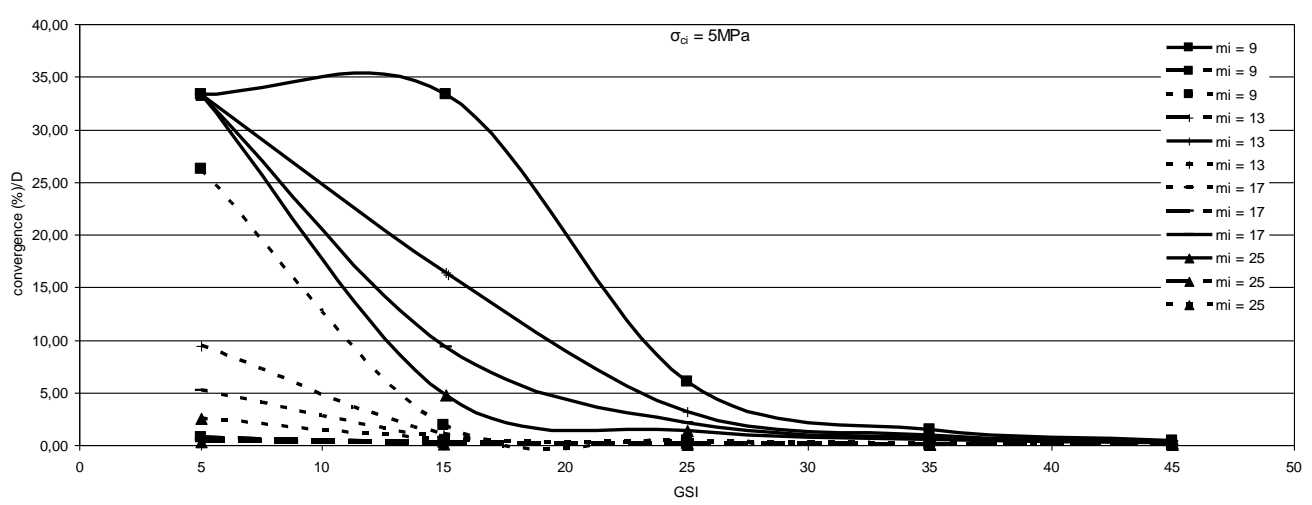

Figure 5 - Convergence of a tunnel versus GSI for various depths and $\mathbf{m}_{\mathrm{i}}$ Uniaxial compressive strength equal to $5 \mathrm{MPa}$.

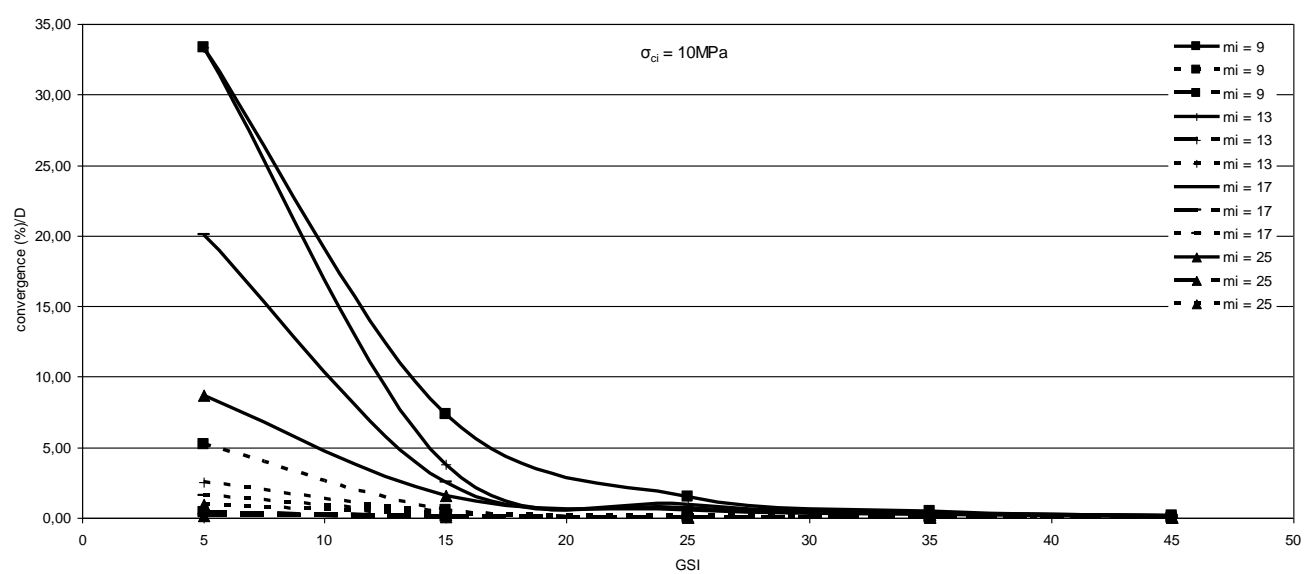

Figure 6 - Convergence of a tunnel versus GSI for various depths and $\mathrm{m}_{\mathrm{i}}$ Uniaxial compressive strength equal to $10 \mathrm{MPa}$.

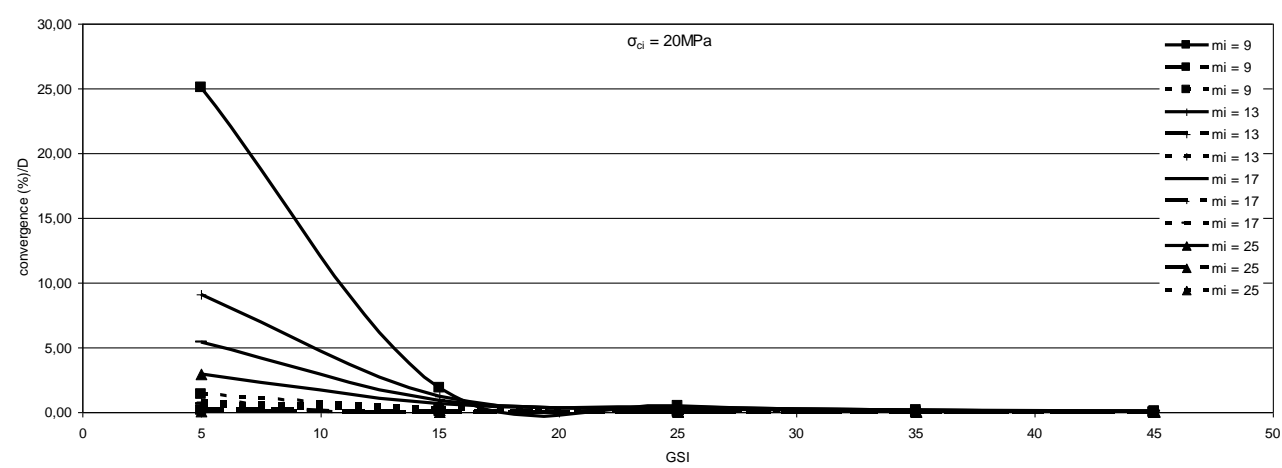

Figure 7 - Convergence of a tunnel versus GSI for various depths and $\mathrm{m}_{\mathrm{i}}$ Uniaxial compressive strength equal to 20MPa. 


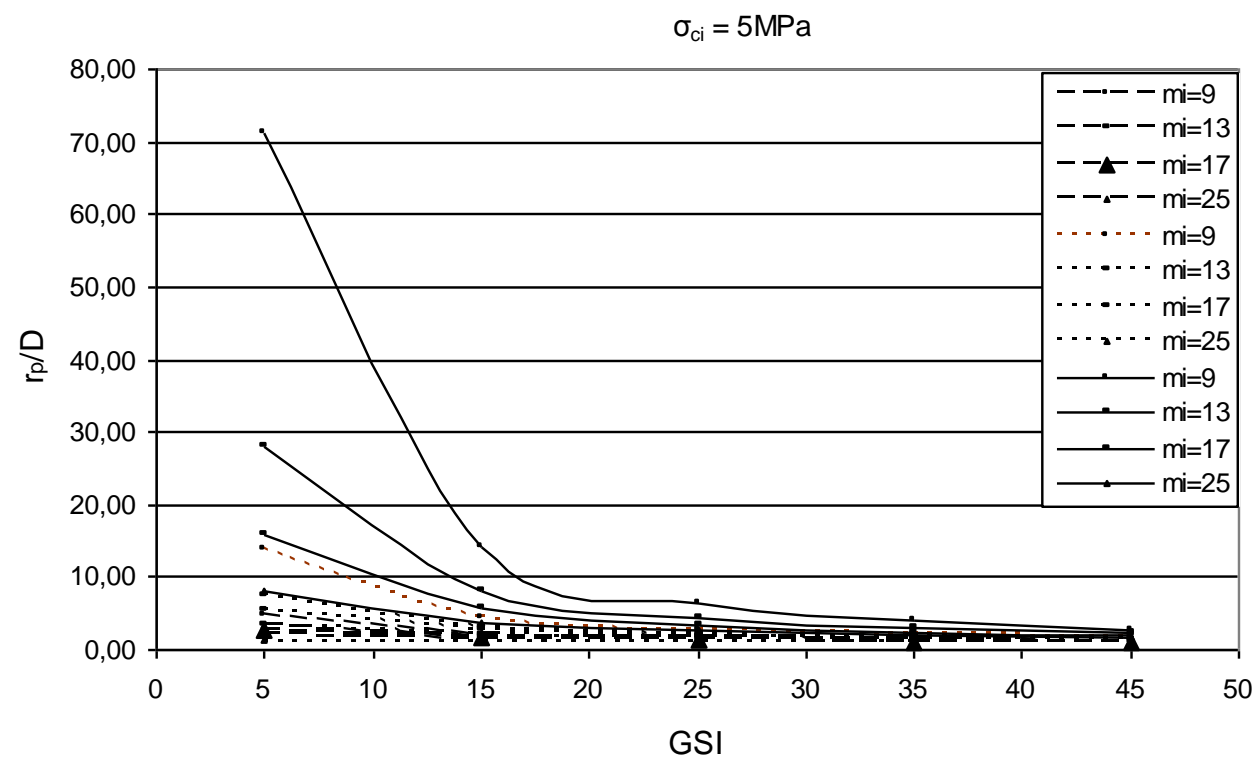

Figure 8 - Radius of plastic zone of an unsupported tunnel versus GSI for various depths and $\mathrm{m}_{\mathrm{i}}$ Uniaxial compressive strength equal to $5 \mathrm{MPa}$.

\section{References}

Brown E. T. 1981. Rock characterization, testing and monitoring - ISRM suggested methods. Pergamon, Oxford, pp 171-183.

Duncan-Fama M. E. 1993. Numerical modeling of yield zones in weak rocks. In Hudson, J. A., ed., Comprehensive rock engineering, 2, 49-75. Oxford: Pergamon Press.

Hoek E. 2012. Rock-Support Interaction analysis for tunnels in weak rock masses. Available online at: www.rocscience.com.

Hoek E. 1998a. Tunnel support in weak rock. Keynote address, Symposium of Sedimentary Rock Engineering, Taipei, Taiwan, November 20-22.

Hoek E. 1998b. Reliability of Hoek-Brown estimates of rock mass properties and their impact on design. Technical note, Int. J. Rock Mech. Min. Sc, 35(I), 63-68.

Hoek E. and Brown E. T. 1980. Empirical strength criterion for rock masses, J. Geotech. Eng Div., ASCE 106 (GT9), 1013-1035.

Hoek E. Carranza-Torres C.T. and Corkum B. 2002. Hoek-Brown failure criterion - 2002 edition, Proc. North American Rock Mechanics Society. Meeting in Toronto in July.

Hoek E. and Karzulovic A. 2000. Rock mass properties for surface mines. In Hustralid, W., A., McCarter, M. K., and van Zyl, D. J. A. (eds). Slope Stability in Surface Mining, Colorado: Society for Mining, Metallurgical and Exploration (SME), Littleton, pp. 59-70.

Marinos P. and Hoek E. 2000 GSI - a geologically friendly tool for rock mass strength estimation, Proc. of GeoEng2000 conference, Melbourne, Australia. 